\title{
Timing of corticosteroids impacts mortality in hospitalized COVID-19 patients
}

\author{
Amit Bahl ${ }^{1}$. $\cdot$ Steven Johnson ${ }^{1} \cdot$ Nai-Wei Chen ${ }^{2}$
}

Received: 10 December 2020 / Accepted: 22 January 2021 / Published online: 5 February 2021

(c) Società Italiana di Medicina Interna (SIMI) 2021

\begin{abstract}
The optimal timing of initiating corticosteroid treatment in hospitalized patients is unknown. We aimed to assess the relationship between timing of initial corticosteroid treatment and in-hospital mortality in COVID-19 patients. In this observational study through medical record analysis, we quantified the mortality benefit of corticosteroids in two equally matched groups of hospitalized COVID-19 patients. We subsequently evaluated the timing of initiating corticosteroids and its effect on mortality in all patients receiving corticosteroids. Demographic, clinical, and laboratory variables were collected and employed for multivariable regression analyses. 1461 hospitalized patients with confirmed COVID-19 were analyzed. Of these, 760 were also matched into two equal groups based on having received corticosteroid therapy. Patients receiving corticosteroids had a lower risk of death than those who did not (HR 0.67, 95\% CI $0.67-0.90 ; p=0.01$ ). Timing of corticosteroids was assessed for all 615 patients receiving corticosteroids during admission. Patients receiving first dose of corticosteroids $>72 \mathrm{~h}$ into hospitalization had a lower risk of death compared to patients with first dose at earlier time intervals (HR $0.56,95 \%$ CI $0.38-0.82 ; p=0.003)$. There was a mortality benefit in patients with $>7$ days of symptom onset to initiation of corticosteroids (HR 0.56, 95\% CI 0.33-0.95; $p=0.03$ ). In patients receiving oxygen therapy, corticosteroids reduced risk of death in mechanically ventilated patients (HR $0.38,95 \%$ CI $0.24-0.60 ; p<0.001$ ) but not in patients on high-flow or other oxygen therapy (HR $0.46,95 \%$ CI $0.20-1.07 ; p=0.07$ ) and (HR 0.84, 95\% CI $0.35-2.00 ; p=0.69$ ), respectively. Timing of corticosteroids initiation was related to in-hospital mortality for COVID-19 patients. Time from symptom onset $>7$ days should trigger initiation of corticosteroids. In the absence of invasive mechanical ventilation, corticosteroids should be initiated if the patient remains hospitalized at $72 \mathrm{~h}$. Hypoxia requiring supplemental oxygen therapy should not be a trigger for initiation of corticosteroids unless the timing is appropriate.
\end{abstract}

Keywords Corticosteroids · Timing · COVID-19 $\cdot$ Coronavirus $\cdot$ Treatment $\cdot$ Mortality

\section{Introduction}

The novel coronavirus (severe acute respiratory syndrome coronavirus 2, SARS-CoV-2) has spread rapidly to nearly every continent across the globe in a matter of months. [1, 2] The United States is the world leader in number of cases and deaths with little signs of reversing trends in the near future $[2,3]$. Aside from social distancing and masking to prevent disease transmission, there are currently no cures for

Amit Bahl

Amit.bahl@beaumont.edu

1 Department of Emergency Medicine, Beaumont Hospital, Royal Oak, MI, USA

2 Beaumont Health Research Institute, Royal Oak, MI, USA
COVID-19 [4]. While a number of investigational therapies have been used for infected patients, most treatments have been ineffective or marginally beneficial in altering the disease course or reducing mortality. [5, 6]

With the recent publication from the RECOVERY collective, corticosteroids have become the first therapeutic option for COVID-19 patients that has shown any mortality benefit [7]. While their data showed a clear benefit to patients requiring respiratory support, it is still unclear when the optimal time to initiate corticosteroid therapy is. Prior research on SARs-CoV suggested that "early" initiation of corticosteroid therapy resulted in prolonged clearance of viral RNA from the plasma [8]. Indeed the evidence from the RECOVERY collaborative also suggests that benefit from corticosteroids is clear only after $>7$ days since symptom 
onset, suggesting that timing of administration is a key element in its effectiveness.

While the RECOVERY trial and some smaller investigations have suggested early corticosteroid therapy may improve mortality outcomes, there is limited evidence available and no clear recommendations on when corticosteroids should be initiated [7,9]. It is our objective to assess the optimal timing to initiate corticosteroid therapy in hospitalized COVID-19 patients to improve in-hospital mortality.

\section{Methods}

\section{Study design and participants}

This was observational study through medical record analysis to assess the impact of initial timing of systemic corticosteroid therapy on mortality for hospitalized patients with COVID-19. The study was approved by the Institutional Review Board at the home institution. Written informed consent requirement was waived due to the rapid emergence of COVID-19. Data were analyzed and interpreted by the authors. We adopted propensity score methods to reduce the effects of confounding within our patient population to ascertain the impact of corticosteroid therapy on mortality. The mortality benefit was assessed via one-to-one matched analysis and additional analyses included all COVID-19 patients hospitalized during our study period were used to examine the robustness of the results of the matching analysis. These methods established that the mortality benefit from corticosteroids existed in our study population, controlling for the influence of the confounders.

The study was conducted at Beaumont Health, an eighthospital acute care regional health system caring for 2.2 million people across the communities within the Metro Detroit catchment area. The hospitals range from a large tertiary care academic center to intermediate-sized and smaller community hospitals. As the epidemic evolved, the health system converted one of the smaller hospitals to a complete COVID-19 center, including converting the emergency department into additional intensive care beds. As the surge in COVID-19 volume developed across the region, hospital systems collaborated to optimize the transfer process and accommodate capacity constraints. While many patients were transferred within Beaumont Health, many patients were also transferred to other hospitals.

\section{Data source}

Data were obtained from the integrated electronic health record (EHR; Epic Systems, Verona, WI). Patients over
18 years of age who were admitted with COVID-19 from March 1 through March 31, 2020 were included. All patients had a laboratory-confirmed case of COVID-19 as defined by a positive result on a reverse-transcriptasepolymerase-chain-reaction (RT-PCR) test of nasopharyngeal swab. Exclusions consisted of patients who left the hospital against medical advice or were transferred to external hospitals. Transfers within Beaumont Health were included as investigators had full access to these medical records. Epidemiological, demographic, therapeutic, clini$\mathrm{cal}$, and outcomes data were extracted. The integrity of the data was verified by two attending emergency medicine physicians.

Hospital admission was based on the clinical judgment of the treating emergency medicine provider. Laboratory and radiological testing was conducted at the discretion of the treating physicians. After initial COVID laboratory testing, patients were not routinely serially tested to evaluate for clearance of acute infection due to paucity of testing supplies. Discharge disposition post-hospitalization was based on patients' clinical condition. Patients were either discharged to home, skilled nursing facility or rehabilitation, hospice, or expired in the hospital.

Admission data included demographics, such as age, race, and gender. Clinical data included comorbidities, body mass index (BMI), number of previous ED visits within the past 6 months, vital signs including lowest oxygen level on room air within first $24 \mathrm{~h}$ of admission and maximum temperature, and laboratory findings. Common laboratory analyses included complete blood count (CBC) with absolute lymphocyte count, metabolic chemistry panel (BMP/CMP), lactate dehydrogenase, lactic acid, procalcitonin, troponin, ferritin, and D-dimer. Laboratory data depicted the first test result occurring within the first $24 \mathrm{~h}$ of presentation to the ED.

Hospital treatment data included use of systemic corticosteroids, adjunctive medical therapies, and oxygen and ventilation therapy. Systemic glucocorticoids and mineralocorticoids were included in the analysis with various routes of administration. Data on the use of different medications were made available to us via EHR in the form of name and dosage ordered. These data did not include frequency of administration. We identified all steroidclass medications within this list and then excluded some of these medications from our analysis. We attempted to exclude any steroids with very low dosages that appeared to be used for chronic conditions as well as steroids that are generally used for specific diagnoses. These exclusions included medications, such as fludrocortisone, doses of prednisone $10 \mathrm{mg}$ or less, and any inhaled steroids. See appendix for full list of corticosteroids as the data were extracted from the EHR as well as which steroids were included and excluded in the analysis. 


\section{Statistical analysis}

We continuously analyzed consecutive patients with COVID-19 from an existing study cohort [10]. Bivariate analyses were stratified by receipt of corticosteroid treatment using means \pm standard deviations and medians with interquartile ranges (IQRs) for continuous variables and frequencies with percentages for categorical variables. Cox proportional hazards regression models were used to assess the association between corticosteroid use and the mortality in hospital. We applied the test for proportionality assumption based on the Schoenfeld residuals. Stratified Cox regression was further applied to adjust the potential non-proportional hazards. An initial multivariable Cox regression model was built, controlling for demographic characteristics, laboratory tests, and clinical variables including vital signs, coexisting medical therapies and Charlson weighted index of comorbidities. In addition, to correct for the nonrandomized treatment administration of corticosteroids, a Cox model that used the inverse probability treatment weighting (IPTW) with propensity score was employed to reduce the effects of observed confounding. The propensity score for receipt of corticosteroid treatment was constructed from a multivariable logistic regression model with the c-statistic of 0.81 that included the same covariates as the multivariable Cox regression. Moreover, a propensity score 1:1 ratio matching was also conducted using a caliper of 0.20 without replacement matching. In the propensity score matching, the quality of matching was examined on ability to evaluate comparability of corticosteroid and non-corticosteroid recipients in the matched cohort using the standardized difference of 0.1 or 0.2 . Kaplan-Meier method was used to assess differences in survival between the propensity score-matched corticosteroid and non-corticosteroid recipients. Missing data were imputed by the procedure of multiple imputation [10]. In analysis, the effect of corticosteroid treatment on inhospital mortality was combined from 20 imputed datasets, accounting for the additional variability introduced by the multiple imputation. All statistical tests were two-sided, with $p<0.05$ considered to be statistically significant. Analyses were performed using R-4.0.2 (R Foundation for Statistical Computing) and SAS v9.4 (SAS Institute, Inc., Cary, NC).

\section{Results}

1461 patients with laboratory-confirmed COVID-19 were admitted at Beaumont Health between March 1 and March 31, 2020. Patients were defined as receiving corticosteroids if administered after arrival at the emergency department and during follow-up period. $615(42.1 \%)$ received corticosteroid and 846 (57.9\%) did not. For the treatment efficacy portion of our analysis, propensity matching resulted in 770 patients with the equal matching ratio on treatment with or without corticosteroids. Table 1 illustrates demographic, clinical, and laboratory data stratified by treatment with or without corticosteroids for the entire and matched cohorts. The standardized differences for all patient characteristics were substantially smaller than $10 \%$ in propensity matching cohort than those in the entire cohort. The imbalance in patient characteristics between corticosteroid and noncorticosteroid was controlled after matching.

The overall mortality rate was $22.4 \%$ (327 out of 1461 ). In a multivariable analysis of the entire cohort, treatment with corticosteroids was associated with a significantly lower risk of in-hospital death [hazard ratio (HR) $0.67,95 \%$ confidence interval (CI) $0.50-0.90 ; p=0.01]$. The multivariable IPTW regression model and regression with propensity matching produced the similar results (Table 2). Kaplan-Meier survival curves for the propensity score-matched corticosteroids and non- corticosteroids groups are shown in Fig. 1. Once mortality benefit was established, the timing of initial corticosteroid therapy was evaluated using the entire cohort of COVID-19 patients who had received corticosteroids during our evaluation period.

615 COVID-19 patients who had received corticosteroids during hospitalization were evaluated. Average age was $63.3 \pm 14.5,42.8 \%$ were female and $63.3 \%$ of patients identified as Black or African American. The most common comorbidity was hypertension existing in $57.2 \%$ of patients. The average Charlson weighted score was $3.2 \pm 2.4$. The majority of patients within the corticosteroid group were hypoxic at initial presentation with $76.9 \%$ having a pulse ox $<94 \%$ on room air upon arrival to the emergency department. $84.9 \%$ had an initial D-dimer $>500 \mathrm{ng} / \mathrm{mL}, 83.7 \%$ had an initial CRP $>50 \mathrm{mg} / \mathrm{L}$, and only $25.2 \%$ had an initial lactate $\geq 2 \mathrm{mmol} / \mathrm{L}$ (Table 1 ).

Timing of corticosteroid administration was related to inhospital death. In 615 patients that received corticosteroids, results of the multivariable analysis indicate that compared to the first dose within $24 \mathrm{~h}$, the first dose at $>72 \mathrm{~h}$ was associated with significant reduction in mortality (HR $0.56,95 \%$ CI $0.38-0.82 ; p=0.003)$. When corticosteroids were initiated less than $72 \mathrm{~h}$ into hospital course, there was no clear benefit or harm in relation to mortality (Table 3, Fig. 2).

Timing of corticosteroid administration was also relevant to survival when considering timing of symptom onset to initiation of therapy. We confirmed the findings of the Recovery collaborative that there was no mortality benefit for steroids initiated $<7$ days from symptom onset. Table 4 illustrates the mortality impact when time from symptom onset was considered for successive time intervals. There was a mortality benefit in patients with $>7$ days since symptom onset (HR 0.56, 95\% CI 0.33-0.95; $p=0.03$ ).

Additionally, we analyzed all admitted COVID-19 patients receiving oxygen therapy to assess the difference 
密

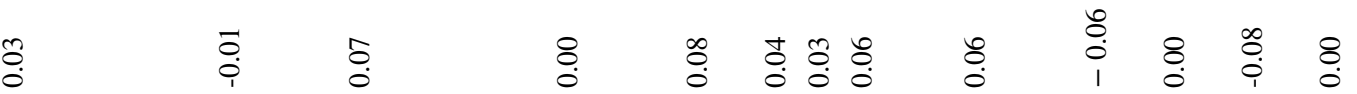

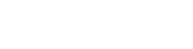

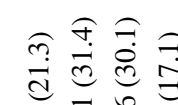

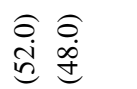

$\stackrel{\substack{\infty \\ \infty}}{\infty}$

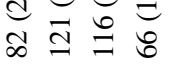

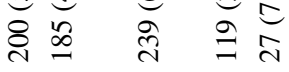

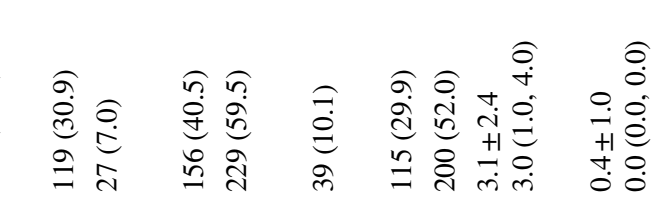

กิ

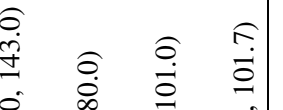

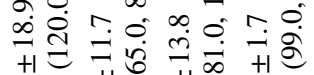

r. ๙ூ

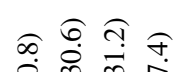

สิ

¿্⿳亠丷厂

永

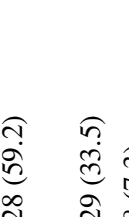

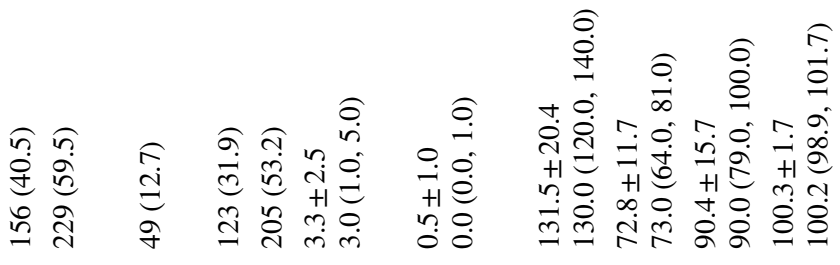

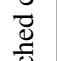

कृ

तิ

\begin{tabular}{ll}
0 & \\
\hdashline & $\infty$ \\
1 & 0 \\
\hline & 0
\end{tabular}

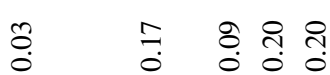

ชำ

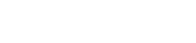

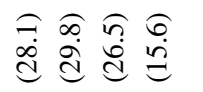

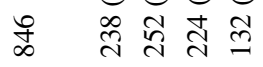

守

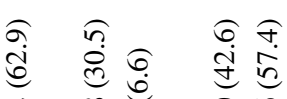

它

ลิ

के

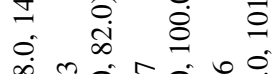

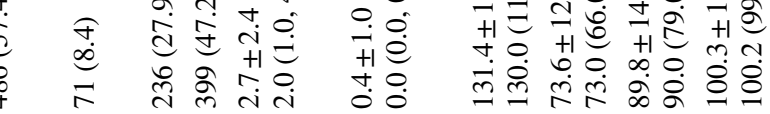

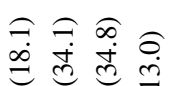

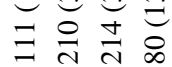

î

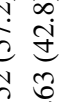

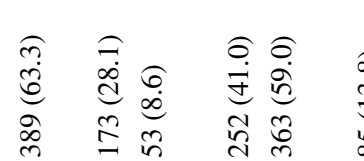

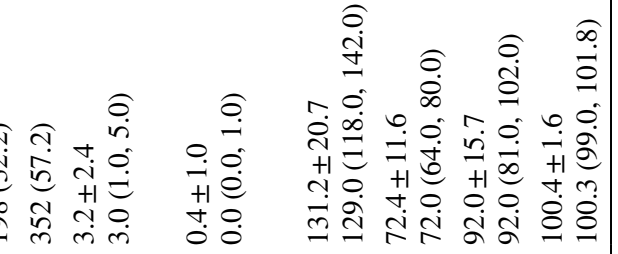

莡

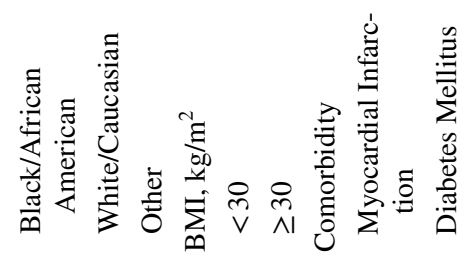

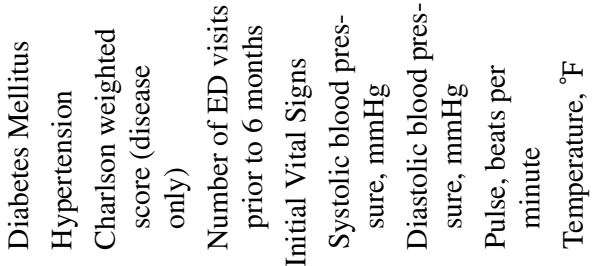




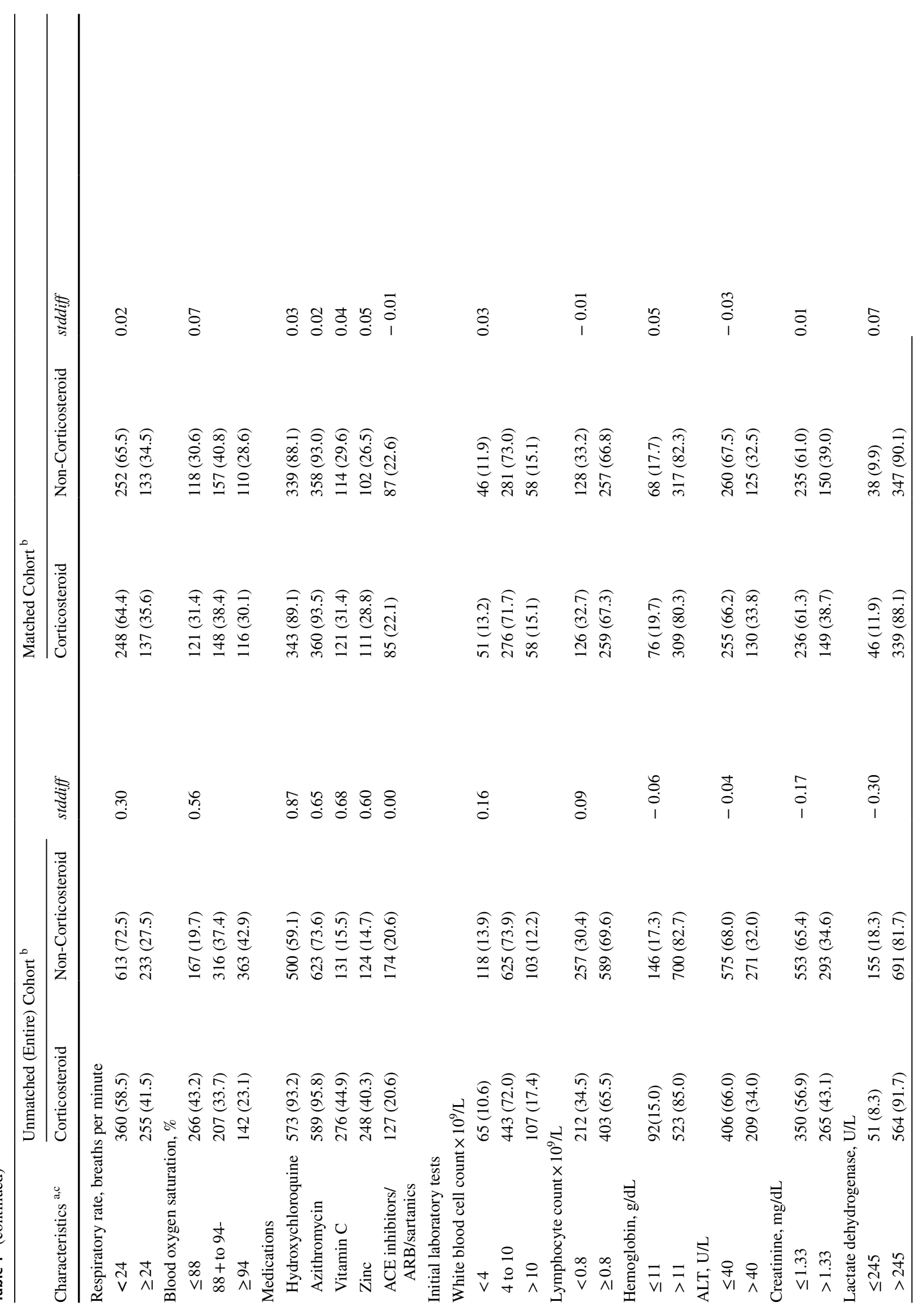




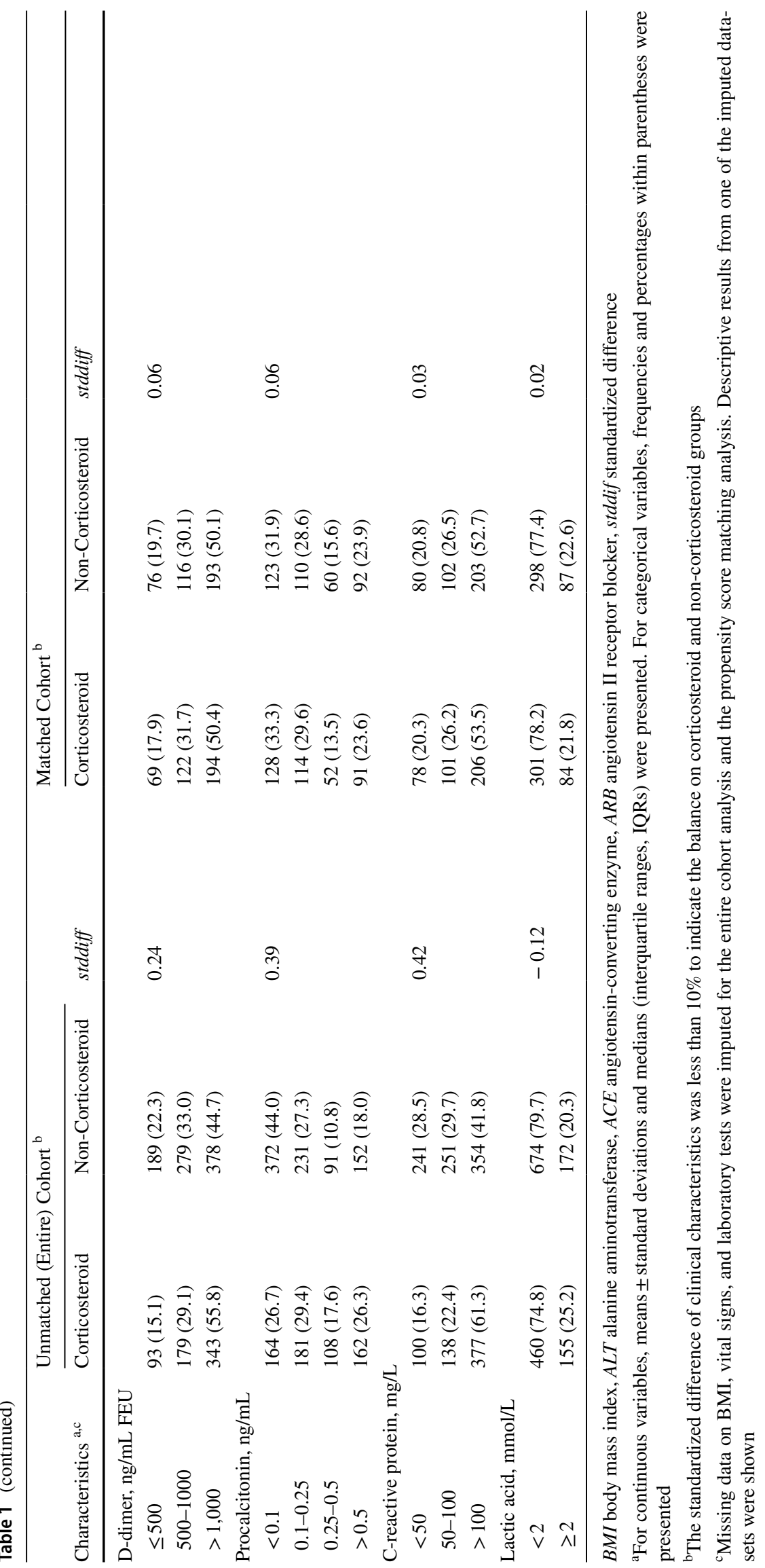


Table 2 Association between corticosteroid use and in-hospital mortality
Methods $^{\text {a,b,c,d }} \quad$ HR $(95 \%$ CI) Corticosteroid versus $\quad p$ value Non-Corticosteroid

Multivariable analysis

$0.67(0.50-0.90) \quad 0.01$

Multivariable analysis adjusted for propensity score

$0.67(0.50-0.90) \quad 0.01$

Inverse probability weighting of pooling propensity score

$0.68(0.52-0.90)$

0.01 analysis

Propensity score matching analysis

$0.67(0.48-0.93)$

0.02

$H R$ hazard ratio, $C I$ confidence interval

${ }^{a}$ Multivariable Cox regression analysis in the entire cohort, with stratification on race and azithromycin, was adjusted for age, gender, BMI, myocardial infarction, diabetes mellitus, hypertension, Charlson weighted score, number of ED visits prior to 6 months, initial vital signs, current medications, and laboratory tests on presentation

${ }^{\mathrm{b}}$ Multivariable Cox regression analysis adjusted for propensity score was a multivariable Cox model with the same strata, covariates, and an additional adjustment for the propensity score in the entire cohort

${ }^{c}$ Inverse probability weighting of pooling propensity score analysis was a multivariable Cox model with the same strata, covariates, and the stabilized weight based on the propensity score in the entire cohort

${ }^{\mathrm{d}}$ Propensity score matching analysis was Cox regression in the matched cohort

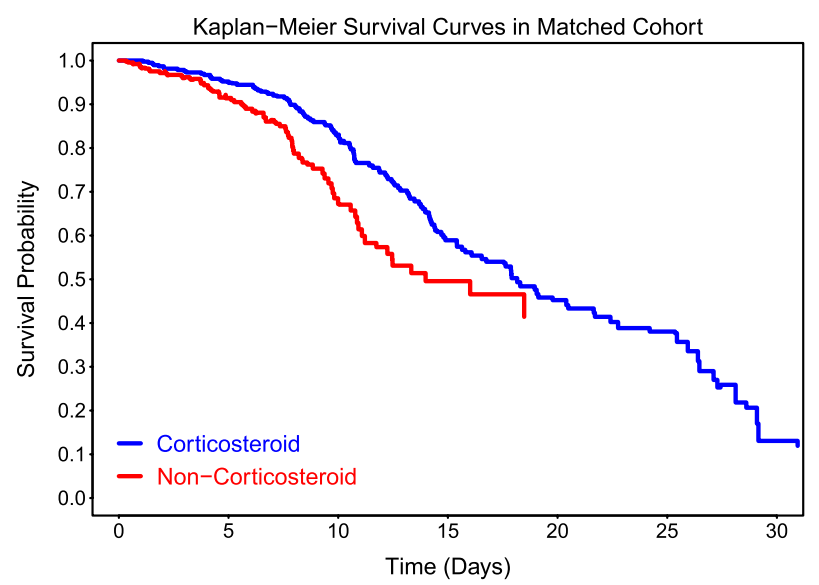

Figure 1. Kaplan-Meier survival curve for corticosteroids treatment. Figure shows overall survival for propensity score-matched patients treated with or without corticosteroids. The estimated survival curves were pooled from 20 imputed datasets

Table 3 Association between corticosteroid administration and inhospital mortality on corticosteroid recipients

\begin{tabular}{lllll}
\hline Initial corticosteroid & $\mathrm{n}$ & Death & HR $(95 \% \mathrm{CI})^{\text {a }}$ & $p$ value \\
\hline$\leq 24 \mathrm{~h}$ & 206 & 64 & Reference & - \\
24 to $48 \mathrm{~h}$ & 95 & 43 & $1.19(0.79-1.81)$ & 0.41 \\
48 to $72 \mathrm{~h}$ & 70 & 21 & $0.79(0.46-1.34)$ & 0.38 \\
$>72 \mathrm{~h}$ & 244 & 90 & $0.56(0.38-0.82)$ & 0.003 \\
\hline
\end{tabular}

$\mathrm{HR}=$ hazard ratio $; \mathrm{CI}=$ confidence interval

${ }^{a}$ Multivariable Cox model was adjusted for age, gender, BMI, myocardial infarction, diabetes mellitus, hypertension, Charlson weighted score, number of ED visits prior to 6 months, initial vital signs, current medications, and laboratory tests on presentation

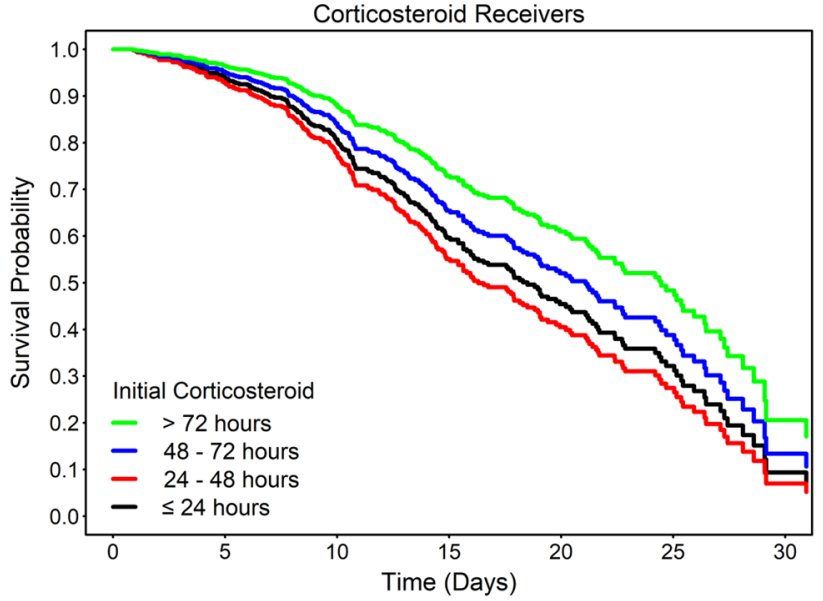

Figure 2. Survival curve for the timing of corticosteroids treatment. Figure shows overall survival of study patients associated with the initial receipt of corticosteroids treatment during the hospitalization. The direct adjusted survival curves were estimated based on a multivariable analysis and pooled from 20 imputed datasets

between level of oxygen requirement and mortality as it related to corticosteroid treatment. In separate multivariable IPTW regression analyses of 1347 patients receiving oxygen therapy, corticosteroids reduced in-hospital mortality significantly in those patients requiring invasive mechanical ventilation (HR 0.38, 95\% CI 0.24-0.60; $p<0.001)$. Patients on high-flow oxygenation therapy had a marginal mortality benefit on corticosteroids treatment (HR 0.46, 95\% CI 0.20-1.07; $p=0.07$ ). Patients receiving oxygen therapy via other routes did not experience a mortality benefit (HR $0.84,95 \%$ CI $0.35-2.00 ; p=0.69$ ) (Table 5 and Fig. 3). 
Table 4 Association between initial corticosteroid use since symptom onset and in-hospital mortality on corticosteroid recipients

\begin{tabular}{lllll}
\hline $\begin{array}{l}\text { Initial corticosteroid use } \\
\text { since symptom onset }{ }^{\mathrm{a}}\end{array}$ & $n$ & Death & HR $(95 \% \mathrm{CI})^{\mathrm{b}}$ & $p$ value \\
\hline$\leq 3$ days $(72 \mathrm{~h})$ & 56 & 25 & Reference & - \\
$4-7$ days & 149 & 59 & $0.88(0.51-1.53)$ & 0.66 \\
$>7$ days & 366 & 118 & $0.56(0.33-0.95)$ & 0.03 \\
\hline
\end{tabular}

$H R$ hazard ratio, $C I$ confidence interval

${ }^{\mathrm{a}}$ Corticosteroid recipients who had records of symptom onset were used for analysis $(n=571)$

${ }^{\mathrm{b}}$ Multivariable Cox model was adjusted for age, gender, BMI, myocardial infarction, diabetes mellitus, hypertension, Charlson weighted score, number of ED visits prior to 6 months, initial vital signs, current medications, and laboratory tests on presentation

\section{Discussion}

Our analysis demonstrated that timing is a key element in the effectiveness of corticosteroids in COVID-19. We found that initiation of corticosteroids at greater than $72 \mathrm{~h}$ duration of hospitalization offered a significant mortality benefit. Treatment prior to this time period did not reduce the likelihood of death. While some evidence has suggested that early use of corticosteroids may be beneficial in hospitalized COVID-19, there have been no previous clear recommendations for timing of initial treatment dose. [9] It is noteworthy that in other similar respiratory illnesses, the evidence supports delayed use or withholding corticosteroids. In an evaluation of SARS patients, early initiation of corticosteroids increased plasma viral load. [8] Among patients with influenza pneumonia, corticosteroids have been shown to increase mortality. [11] Contrary to the findings from Fadel et al.'s publication in which earlier therapy demonstrated

Table 5 Association between corticosteroid use and in-hospital mortality for oxygen therapy

\begin{tabular}{|c|c|c|c|c|c|}
\hline Therapy & Medication Use & Mortality & & $\begin{array}{l}\text { HR }(95 \% \text { CI) (Reference: } \\
\text { Non-Corticosteroid) }\end{array}$ & $p$ value \\
\hline \multirow[t]{2}{*}{ A. Invasive Mechanical Ventilation ${ }^{\mathrm{a}}$} & Corticosteroid & $168 / 243$ & $(69.1 \%)$ & $0.38(0.24-0.60)$ & $<0.001$ \\
\hline & Non-Corticosteroid & $51 / 65$ & $(78.5 \%)$ & & \\
\hline \multirow[t]{2}{*}{ B. High Flow Oxygen ${ }^{a}$} & Corticosteroid & $38 / 153$ & $(24.8 \%)$ & $0.46(0.20-1.07)$ & 0.07 \\
\hline & Non-Corticosteroid & $26 / 63$ & $(41.3 \%)$ & & \\
\hline \multirow[t]{2}{*}{ C. Other Oxygen Therapy ${ }^{\mathrm{a}}$} & Corticosteroid & $12 / 214$ & $(5.6 \%)$ & $0.84(0.35-2.00)$ & 0.69 \\
\hline & Non-Corticosteroid & $31 / 609$ & $(5.1 \%)$ & & \\
\hline
\end{tabular}

$H R$ hazard ratio, $C I$ confidence interval

${ }^{a}$ Multivariable Cox model with inverse probability weighting of propensity score was adjusted for age, gender, BMI, myocardial infarction, diabetes mellitus, hypertension, Charlson weighted score, number of ED visits prior to 6 months, initial vital signs, current medications, and laboratory tests on presentation
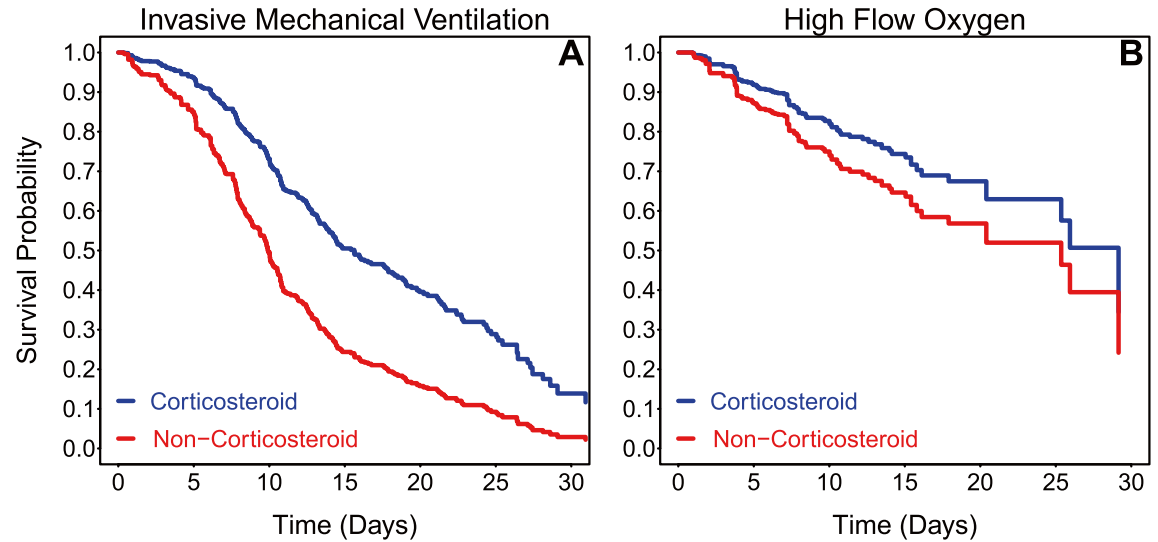

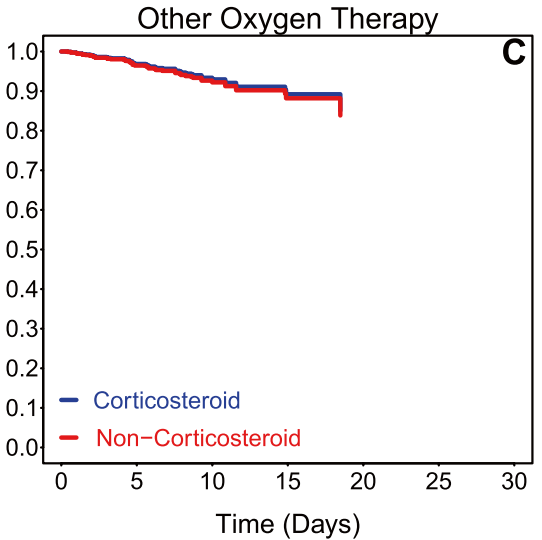

Figure 3. Survival curve for receipt of corticosteroids treatment by oxygen therapy. Figure shows overall survival of study patients associated with receipt of corticosteroids treatment for patients receiving oxygen therapy with different levels of oxygen requirement. The direct adjusted survival curves were estimated based on the inverse probability weighting of propensity score analyses and pooled from 20 imputed datasets 
benefit, we did not find a mortality benefit with treatment initiated prior to $72 \mathrm{~h}$ since hospitalization. [9] Both the treatment and placebo groups in the RECOVERY collaborative had a median number of days since hospitalization of 2 making it difficult to draw any conclusions on optimal timing of corticosteroid initiation as it related to hospitalization. [7] They did however show that dexamethasone showed no mortality benefit among patients with $\leq 7$ days since symptom onset, which we also observed within our cohort. [7]

We were able to reinforce the findings of recent studies that corticosteroid therapy was associated with a significantly lower in-hospital mortality among admitted COVID19 patients. [7, 9, 12, 13] Our study also involved assessment of a well-matched cohort of hospitalized, COVID-19 patients differentiated based on corticosteroid usage. The propensity-score-matched approach was used to construct a randomized experiment-like situation by comparing corticosteroid and non-corticosteroid groups with similar observed characteristics. The finding of a mortality benefit from corticosteroid was robust with regard to results obtained using probability-weighted and multivariable regression analyses. Prior trials have mostly only included ICU patients, while our cohort was composed of all admitted patients $[12,14,15]$.

The subgroup of patients that benefited the most from corticosteroid therapy in our analysis was the critically ill patients receiving invasive mechanical ventilation. This was similar to the results from the RECOVERY collaborative in which patients requiring ventilator support had the greatest reduction in mortality. The mortality benefit of corticosteroids related to hypoxia and other modes of oxygenation was less clear. In our cohort of 615 patients receiving corticosteroids, the degree of hypoxia was profound and unique compared to the RECOVERY cohort with nearly $77 \%$ of our patients presenting to the ED with hypoxia (pulse ox less than $94 \%$ on room air). Comparatively, a large subset of patients (24\%) in the RECOVERY cohort did not even require supplemental oxygen. The data in our cohort suggest hypoxia alone prior to $72 \mathrm{~h}$ of hospitalization may not be an indication for initiation of corticosteroid therapy. Fadel et al.'s investigation regarding early versus delayed in corticosteroids in COVID19 hypoxic patients (4 L via nasal cannula) also suggested that the benefit from timing of corticosteroid administration is likely independent of hypoxia. We were able to categorize hypoxic patients into three groups: invasive mechanical ventilation, high-flow therapy, and other including nasal cannula and non-re-breather. In contrast to the data presented by the RECOVERY collaborative, we did not observe a mortality benefit from corticosteroids among patients who only required oxygen via nasal cannula or non-re-breather. There was a marginally statistically significant benefit among patients requiring high-flow therapy and a clear significant mortality benefit among patients requiring mechanical ventilation. Both of these results are consistent with many recent publications suggesting that critically ill COVID-19 patients benefit from corticosteroids. $[7,9,12,13]$

The retrospective design of the study was a limitation as we could not control the type, dose, or frequency of corticosteroid that was administered. EHR data were collected as: steroid name, dose, and route; this formatting created some difficulty in analyzing specific steroids and doses administered, particularly with dosage changes and in patients that received more than one type of steroid. Nevertheless, we were able to closely estimate the breakdown amongst steroid types and provide ranges for dosages. In our study cohort, approximately $87 \%$ received methylprednisolone, $13 \%$ received prednisone, and $4 \%$ received dexamethasone. As discussed above, we attempted to limit our analysis to steroid types and doses that would be used in the treatment of ARDS or sepsis, however, it is possible that some steroids were prescribed for other indications. Additionally, other investigational therapies may have been given in combination with corticosteroids and the impact on mortality was not specifically assessed in this study. Another limitation was that we were unable to evaluate the impact of corticosteroids on patients not receiving supplemental oxygen as only $7.8 \%$ of our cohort did not receive any oxygen therapy. The RECOVERY data suggested that patients not receiving oxygen did not benefit from corticosteroids and may possibly be harmed from this treatment. Given the rapid spike in cases during the investigational period, ED practitioners generally did not admit any patients who did not require supplemental oxygen. Therefore, it was difficult to draw any conclusions on the use of corticosteroids in COVID-19 patients who did not requiring oxygen. Finally, $63 \%$ of our population identified as African American, therefore, the outcomes observed within our study population may not be generalizable to a more diverse group.

Timing of corticosteroids initiation was related to in-hospital mortality in our cohort of COVID-19 patients. Time from symptom onset $>7$ days should trigger initiation of corticosteroids. In the absence of invasive mechanical ventilation, corticosteroids should be withheld for the first $48 \mathrm{~h}$ of hospitalization, may be considered during the period of 48 to $72 \mathrm{~h}$, and should be initiated if the patient remains hospitalized at $72 \mathrm{~h}$. Hypoxia requiring supplemental oxygen therapy should not be a trigger for initiation of corticosteroids unless the timing is appropriate. 


\section{Appendix}

Appendix. List of corticosteroids

\begin{tabular}{|c|c|c|c|}
\hline \multirow[b]{2}{*}{$\begin{array}{l}\text { Included steroids_-as any } \\
\text { given medications were } \\
\text { recorded in EHR }\end{array}$} & \multicolumn{2}{|c|}{$\begin{array}{l}\text { Observed fre- } \\
\text { quency }\end{array}$} & \multirow{2}{*}{$\begin{array}{l}\text { Given dose } \\
\text { (Low, high) }\end{array}$} \\
\hline & $n$ & $(\%)$ & \\
\hline $\begin{array}{l}\text { DEXAMETHASONE } 2 \\
\text { MG PO TABS }\end{array}$ & $1 / 615$ & $(0.16 \%)$ & $10 \mathrm{mg}$ \\
\hline $\begin{array}{l}\text { DEXAMETHASONE } 4 \\
\text { MG PO TABS }\end{array}$ & $1 / 615$ & $(0.16 \%)$ & $16 \mathrm{mg}$ \\
\hline $\begin{array}{l}\text { DEXAMETHASONE } \\
\text { SOD PHOS } 10 \text { MG/ML } \\
\text { IJ SUPERORDERABLE } \\
\text { OHS }\end{array}$ & $11 / 615$ & $(1.79 \%)$ & $(0.8 \mathrm{mg}, 10 \mathrm{mg})$ \\
\hline $\begin{array}{l}\text { DEXAMETHASONE } \\
\text { SOD PHOS } 4 \text { MG/ML } \\
\text { IJ SUPERORDERABLE } \\
\text { OHS }\end{array}$ & $2 / 615$ & $(0.33 \%)$ & $(4 \mathrm{mg}, 10 \mathrm{mg})$ \\
\hline $\begin{array}{l}\text { DEXAMETHASONE } \\
\text { SODIUM PHOSPHATE } \\
10 \text { MG/ML INJ SOLN }\end{array}$ & $3 / 615$ & $(0.49 \%)$ & $10 \mathrm{mg}$ \\
\hline $\begin{array}{l}\text { DEXAMETHASONE } \\
\text { SODIUM PHOSPHATE } \\
4 \text { MG/ML INJ SOLN }\end{array}$ & $11 / 615$ & $(1.79 \%)$ & $(1 \mathrm{mg}, 8 \mathrm{mg})$ \\
\hline $\begin{array}{l}\text { HYDROCORTISONE NA } \\
\text { SUCCINATE PF } 100 \mathrm{MG} \\
\text { INJ SOLR }\end{array}$ & $57 / 615$ & $(9.27 \%)$ & $(12.5 \mathrm{mg}, 100 \mathrm{mg})$ \\
\hline $\begin{array}{l}\text { HYDROCORTISONE SOD } \\
\text { SUCC } 100 \text { MG IJ SOLR } \\
\text { SUPERORDERABLE } \\
\text { OHS }\end{array}$ & $16 / 615$ & $(2.60 \%)$ & $(25 \mathrm{mg}, 100 \mathrm{mg})$ \\
\hline $\begin{array}{l}\text { METHYLPREDNISO- } \\
\text { LONE IVPB 126-999 } \\
\text { MG }\end{array}$ & $1 / 615$ & $(0.16 \%)$ & $500 \mathrm{mg}$ \\
\hline $\begin{array}{l}\text { METHYLPREDNISO- } \\
\text { LONE SODIUM SUCC } \\
125 \text { MG INJ SOLR }\end{array}$ & $187 / 615$ & $(30.41 \%)$ & $(1 \mathrm{mg}, 250 \mathrm{mg})$ \\
\hline $\begin{array}{l}\text { METHYLPREDNISO- } \\
\text { LONE SODIUM SUCC } \\
40 \text { MG INJ SOLR }\end{array}$ & $431 / 615$ & $(70.08 \%)$ & $(20 \mathrm{mg}, 80 \mathrm{mg})$ \\
\hline $\begin{array}{l}\text { METHYLPREDNISO- } \\
\text { LONE TO } 500 \text { MG IVPB } \\
\text { OHS }\end{array}$ & $2 / 615$ & $(0.33 \%)$ & $(40 \mathrm{mg}, 500 \mathrm{mg})$ \\
\hline $\begin{array}{l}\text { PREDNISONE } 20 \text { MG PO } \\
\text { TABS }\end{array}$ & $76 / 615$ & $(12.36 \%)$ & $(10 \mathrm{mg}, 80 \mathrm{mg})$ \\
\hline $\begin{array}{l}\text { PREDNISONE } 50 \text { MG PO } \\
\text { TABS }\end{array}$ & $9 / 615$ & $(1.46 \%)$ & $50 \mathrm{mg}$ \\
\hline $\begin{array}{l}\text { HYDROCORTISONE } \\
\text { (SOLU-CORTEF) } 100 \\
\text { MG INJECTION CABI- } \\
\text { NET OVERRIDE }\end{array}$ & $4 / 615$ & $(0.65 \%)$ & $(45 \mathrm{mg}, 100 \mathrm{mg})$ \\
\hline
\end{tabular}

Appendix. List of corticosteroids

\begin{tabular}{|c|c|c|}
\hline \multirow[b]{2}{*}{$\begin{array}{l}\text { Included steroids-as any } \\
\text { given medications were } \\
\text { recorded in EHR }\end{array}$} & $\begin{array}{l}\text { Observed fre- } \\
\text { quency }\end{array}$ & \multirow{2}{*}{$\begin{array}{l}\text { Given dose } \\
\text { (Low, high) }\end{array}$} \\
\hline & $(\%)$ & \\
\hline $\begin{array}{l}\text { METHYLPREDNISO- } \\
\text { LONE SODIUM SUCCI- } \\
\text { NATE (SOLU-MEDROL) } \\
\text { 125MG / 2ML INJEC- } \\
\text { TION CABINET OVER- } \\
\text { RIDE }\end{array}$ & $(0.16 \%)$ & $125 \mathrm{mg}$ \\
\hline \multicolumn{3}{|c|}{$\begin{array}{l}\text { Note: Each of } 615 \text { patients who were counted as recipients of } \\
\text { corticosteroid treatment was given one or more than one included } \\
\text { steroids during hospitalization }\end{array}$} \\
\hline \multicolumn{3}{|c|}{$\begin{array}{l}\text { Excluded steroids—as any given medications were recorded in } \\
\text { EHR }\end{array}$} \\
\hline \multicolumn{3}{|l|}{$\begin{array}{l}\text { PREDNISONE } 10 \text { MG PO } \\
\text { TABS }\end{array}$} \\
\hline \multicolumn{3}{|l|}{$\begin{array}{l}\text { PREDNISONE } 5 \text { MG PO } \\
\text { TABS }\end{array}$} \\
\hline \multicolumn{3}{|l|}{$\begin{array}{l}\text { BUDESONIDE } 3 \text { MG PO } \\
\text { CPEP }\end{array}$} \\
\hline \multicolumn{3}{|l|}{$\begin{array}{l}\text { PREDNISOLONE } 5 \mathrm{MG} \\
\text { PO TABS }\end{array}$} \\
\hline \multicolumn{3}{|l|}{$\begin{array}{l}\text { HYDROCORTISONE } 10 \\
\text { MG PO TABS }\end{array}$} \\
\hline \multicolumn{3}{|l|}{$\begin{array}{l}\text { PREDNISONE } 1 \text { MG PO } \\
\text { TABS }\end{array}$} \\
\hline \multicolumn{3}{|l|}{$\begin{array}{l}\text { METHYLPREDNISO- } \\
\text { LONE } 4 \text { MG PO TABS }\end{array}$} \\
\hline \multicolumn{3}{|l|}{$\begin{array}{l}\text { FLUTICASONE FURO- } \\
\text { ATE-VILANTEROL } \\
\text { 100-25 MCG/INH } \\
\text { INHAL AEPB }\end{array}$} \\
\hline \multicolumn{3}{|l|}{$\begin{array}{l}\text { FLUTICASONE FURO- } \\
\text { ATE-VILANTEROL } \\
\text { 200-25 MCG/INH } \\
\text { INHAL AEPB }\end{array}$} \\
\hline \multicolumn{3}{|l|}{$\begin{array}{l}\text { BUDESONIDE } 0.5 \\
\text { MG/2ML INHAL SUSP }\end{array}$} \\
\hline $\begin{array}{l}\text { FLUTICASONE PROPI- } \\
\text { ONATE HFA } 44 \text { MCG/ } \\
\text { ACT INHAL AERO }\end{array}$ & & \\
\hline
\end{tabular}

\section{Compliance with ethical standards}

Conflict of interest This manuscript in part or in full has not been submitted or published anywhere. No authors have any relevant conflict of interest disclosures.

Statement of human and animal rights The study was approved by the Institutional Review Board at the home institution.

Informed consent Written informed consent requirement was waived due to the rapid emergence of COVID-19. 


\section{References}

1. Coronavirus disease (COVID-19). https://www.who.int/emerg encies/diseases/novel-coronavirus-2019. Accessed 15 Oct 2020

2. COVID-19 Map - Johns Hopkins Coronavirus Resource Center. https://coronavirus.jhu.edu/map.html. Accessed 15 Oct 2020

3. Coronavirus Disease 2019 (COVID-19) I CDC. https://www.cdc. gov/coronavirus/2019-nCoV/index.html. Accessed 15 Oct 2020

4. Q\&A on coronaviruses (COVID-19). https://www.who.int/emerg encies/diseases/novel-coronavirus-2019/question-and-answershub/q-a-detail/q-a-coronaviruses. Accessed 15 Oct 2020

5. Beigel JH, Tomashek KM, Dodd LE et al (2020) Remdesivir for the Treatment of Covid-19 - Final Report. N Engl J Med 383:1813-1826. https://doi.org/10.1056/NEJMoa2007764

6. Rosenberg ES, Dufort EM, Udo T et al (2020) Association of Treatment With Hydroxychloroquine or Azithromycin With InHospital Mortality in Patients With COVID-19 in New York State. JAMA 323:2493. https://doi.org/10.1001/jama.2020.8630

7. (2020) Dexamethasone in Hospitalized Patients with Covid-19 Preliminary Report. N Engl J Med NEJMoa2021436. https://doi. org/https://doi.org/10.1056/NEJMoa2021436

8. Lee N, Allen Chan KC, Hui DS et al (2004) Effects of early corticosteroid treatment on plasma SARS-associated Coronavirus RNA concentrations in adult patients. J Clin Virol 31:304-309. https://doi.org/10.1016/j.jcv.2004.07.006

9. Fadel R, Morrison AR, Vahia A et al (2020) Early Short-Course Corticosteroids in Hospitalized Patients With COVID-19. Clin Infect Dis 71:2114-2120. https://doi.org/10.1093/cid/ciaa601

10. Bahl A, Van Baalen MN, Ortiz L et al (2020) Early predictors of in-hospital mortality in patients with COVID-19 in a large
American cohort. Intern Emerg Med 15:1485-1499. https://doi. org/10.1007/s11739-020-02509-7

11. Ni Y-N, Chen G, Sun J et al (2019) The effect of corticosteroids on mortality of patients with influenza pneumonia: a systematic review and meta-analysis. Crit Care 23:99. https://doi. org/10.1186/s13054-019-2395-8

12. Sterne JAC, Murthy S, Diaz JV et al (2020) Association Between Administration of Systemic Corticosteroids and Mortality Among Critically Ill Patients With COVID-19. JAMA 324:1330. https:// doi.org/10.1001/jama.2020.17023

13. Corral L, Bahamonde A, Revillas FA delas, et al (2020) GLUCOCOVID: A controlled trial of methylprednisolone in adults hospitalized with COVID-19 pneumonia. medRxiv 2020.06.17.20133579. https://doi.org/https://doi. org/10.1101/2020.06.17.20133579

14. Tomazini BM, Maia IS, Cavalcanti AB et al (2020) Effect of Dexamethasone on Days Alive and Ventilator-Free in Patients With Moderate or Severe Acute Respiratory Distress Syndrome and COVID-19. JAMA 324:1307. https://doi.org/10.1001/ jama.2020.17021

15. Angus DC, Derde L, Al-Beidh F et al (2020) Effect of Hydrocortisone on Mortality and Organ Support in Patients With Severe COVID-19. JAMA 324:1317. https://doi.org/10.1001/ jama.2020.17022

Publisher's Note Springer Nature remains neutral with regard to jurisdictional claims in published maps and institutional affiliations. 